\title{
Sergio Sacchi, Etudes sur les «Illuminations» de Rimbaud
}

\section{Mario Richter}

\section{(2) OpenEdition}

10 Journals

\section{Édition électronique}

URL : https://journals.openedition.org/studifrancesi/39693

DOI : 10.4000/studifrancesi.39693

ISSN : 2427-5856

Éditeur

Rosenberg \& Sellier

\section{Édition imprimée}

Date de publication : 1 décembre 2004

Pagination : 404

ISSN : 0039-2944

\section{Référence électronique}

Mario Richter, «Sergio Sacchi, Etudes sur les «llluminations» de Rimbaud», Studi Francesi [En ligne], 143 (XLVIII | II) | 2004, mis en ligne le 30 novembre 2015, consulté le 19 mai 2021. URL : http://

journals.openedition.org/studifrancesi/39693; DOI : https://doi.org/10.4000/studifrancesi.39693

Ce document a été généré automatiquement le 19 mai 2021.

\section{(c) (i) $\odot$}

Studi Francesi è distribuita con Licenza Creative Commons Attribuzione - Non commerciale - Non opere derivate 4.0 Internazionale. 


\title{
Sergio Sacchi, Etudes sur les «Illuminations» de Rimbaud
}

\author{
Mario Richter
}

\section{RÉFÉRENCE}

SERGIO SACCHI, Etudes sur les «Illuminations» de Rimbaud, Textes recueillis par OLIVIER BIVORT, ANDRÉ GUYAUX et MARIO MATUCCI, Paris, Presses de l'Université de Paris-Sorbonne, 2002, pp. 277.

1 Nous devons cet ouvrage à l'amitié, à l'admiration et à la fidélité qu'une petite équipe d'éminents spécialistes rimbaldiens a voulu témoigner au souvenir de Sergio Sacchi, décédé prématurément voilà six ans. Il s'agit d'un recueil de quinze études que Sacchi avait consacrées aux Illuminations et qu'il avait lui-même projeté de réunir sous forme de livre. Il ne pouvait espérer trouver des amis plus dévoués, plus soucieux de donner un texte tout à fait impeccable, vraiment digne de lui, c'est-à-dire d'un critique que nous admirions tous pour son extrême précision et pour la rigueur de ses procédés herméneutiques.

2 Ecartant l'ordre chronologique de la première présentation en revue de ces commentaires, les Editeurs les ont arrangés selon l'ordre éditorial qu'on a l'habitude d'attribuer aux Illuminations. Ce choix a certainement le mérite de rendre plus aisée et efficace la lecture du livre. Ceux qui cependant désireraient suivre l'évolution réelle de l'approche critique de l'auteur et la succession effective de ses intérêts peuvent avoir facilement recours à la très précise Note bibliographique qui se lit à la page 267.

3 L'ouvrage débute par trois articles à caractère essentiellement méthodologique («Trover une langue», «Voici le temps des exégètes», «Hermétisme, onirisme, aura mythique»). Ces pages donnent d'emblée une idée assez précise de la démarche critique de l'auteur: son argumentation avance en effet avec beaucoup de prudence; se révélant très respectueuse des apports des autres critiques (tous discutés avec grand sérieux), elle se précise progressivement, en cours de route. Suivent les 'lectures' concernant 
Après le Déluge, Enfance, Conte, Vies, Royauté, Phrases, Ouvriers, Ville, Mystique, Aube, Métropolitain, Barbare.

4 L'ouvrage s'achève sur une section consacrée aux «Références» (il s'agit d'une excellente et très précise bibliographie rimbaldienne), sur la «Note bibliographique» déjà citée, et sur un très utile «Index des œuvres et des poèmes de Rimbaud».

5 Le présent volume constitue un instrument de travail précieux et tout à fait nécessaire pour l'avancement des études rimbaldiennes. 